\title{
Scenarios for applying RFID technology in construction project management
}

\author{
Weisheng $\mathrm{Lu}^{1}$, George Q. Huang ${ }^{2}$, and Heng $\mathrm{Li}^{3}$
}

\begin{abstract}
Radio Frequency Identification (RFID) technology has been widely applied in various areas such as retail, electronic transaction, logistic and supply chain management, scientific research, security, etc. It has brought about great benefits in these areas through improving real-time information visibility and traceability. However, a widespread application of RFID in the construction industry has not taken place. One possible reason is that construction practitioners may have not been fully informed of its potentials. This paper aims to investigate various scenarios that can illustrate the uses of RFID technology in construction project management. The research starts from a brief summary of recent developments of RFID technology in different industrial sectors including construction. 16 researchers were split into 3 groups to investigate how RFID can be used in the management of materials, men, and machinery $\left(\mathrm{M}^{3}\right)$ for construction projects. Perspectives for future studies are proposed in order to fully realise the potentials. The research encourages a wider adoption of RFID technology in improving current PM practices. It also provides academia with a platform for further exploring the innovative uses of RFID technology in construction.
\end{abstract}

Keywords: Project management, Radio Frequency Identification, Information management, Information visibility and traceability, Scenarios, Construction

\footnotetext{
${ }^{1}$ Assistant Professor, Dept. of Real Estate and Construction, The University of Hong Kong, Hong Kong S.A.R. Email: wilsonlu@hku.hk

2 Professor, Dept. of Industrial and Manufacturing Systems Engineering, Faculty of Engineering, the University of Hong Kong, Hong Kong S.A.R.

${ }^{3}$ Professor, Dept. of Building and Real Estate, The Hong Kong Polytechnic University, Hong

Kong S.A.R., Email: bshengli@polyu.edu.hk
} 


\section{Introduction}

Increasing demands for speed and efficiency in the face of greater complexity of modern construction projects have given rise to the need for management (Bennett, 1985). Today, there are higher standards for successful construction project management (CPM); traditional success criteria for CPM have been broadened from cost, quality, and time (known as PM triangle) to include safety and environment (Shen et al., 2006). This requires project managers to make better decision to align materials, labour, and machinery based on the information available. Information is recognised as a new element for CPM success; some even proposed the paradigm that doing construction business is essentially making a web of informed decision across its process based on the information and knowledge available (Flanagan and Lu, 2008). How to effectively manage information presents new challenges for contemporary CPM.

Among the many challenges for managing information in CPM, a particularly keen one is to improve real-time information visibility and traceability. Project managers need to acquire real-time information about materials, men, and machinery so as to make prompt and informed decisions. This echoes with Flanagan and Lu (2008) who suggested that the main objective of information management is to make sure that accurate information is always available at the right time in the right format to the right person to support decision making. Here the information could include inventory of materials, positions of construction workers, conditions of machinery, and so on. The increasing complexity of modern construction projects, together with some innovative CPM models such as Just-In-Time (JIT), lean construction, prefabrication, all desires new approaches to provide real-time information with better visibility and traceability.

Notably, in industrial sectors such as logistic and supply chain management (LSCM), manufacturing, RFID technology has been widely discussed. In LSCM scenarios, for example, using RFID technology, such real-time traceability and visibility, enabled at the upstream, are important for increasing the efficiency and quality of supply chain operations, especially towards the downstream (e.g. distribution, wholesale, and retail) (Chappell et al. 2002; Schultz and Woods 2002; Kärkkäinen and Holmström 2002; Angeles 2005; Tajima, 2007). In the manufacturing sector, Huang et al. (2007; 2008a; 2008b) investigated the RFID-based wireless manufacturing jobsites with better real-time information traceability and visibility. However, little attention has been paid to the investigation of RFID technology in construction which is also viewed as an information-based industry in addition to its labor, material, and capital intensive nature (Anumba et al., 2005). In comparison with the heated debates in other sectors, a widespread adoption of the technology has not been seen in real-life construction practices.

The primary aim of this research is to explore the potential applications of RFID technology in CPM. The rest of the paper comprises of five sections. In Section 2, recent developments of RFID technology in different industrial sectors including 
construction are reviewed. Research methods are presented in Section 3. Using a narrative form, Section 4 describes the various scenario cases that illustrate the potential applications of RFID in CPM. These scenarios have been further animated by using Google Sketch Up in our research. Next in Section 5, perspectives for future studies are proposed for fully realising the potentials. Finally, conclusions are drawn. The research encourages the industry to widely adopt RFID technology which has great potentials to improve current PM practice and its performance. It also provides academia with a new platform for further exploring the applications of RFID technology, overcoming its technical and economical hurdles.

\section{Recent developments}

\subsection{Understanding RFID technology}

Few people know about RFID technology although almost everyone today has at least one item with RFID in their wallet (e.g. subway card). In simple terms, RFID is a technology using radio waves of different frequencies for identifying objects. A typical RFID system comprises of a RFID tag and a RFID reader. A RFID tag is often formulated by a microchip which stores data and an integrated antenna serving as a transmitter. There are two types of RFID: the passive RFID and the active RFID where the former one has no power sources inside them but relies on the reader to supply power for wireless communication, and the latter has power sources installed inside.

RFID was firstly introduced as a sister technology to replace barcode system for identifying items. Table 1 is a summary of advantages of RFID by comparing it with barcode system and magnetic strip system. In contrast, it can store a relatively large number of data; for Passive RFID its memory can vary from 128 to 256 bytes while memory of active RFID can range from 32 to 128 kilobytes (KB) (Goodrum et al., 2006). These data can be encrypted to increase data security. It is possible to read data from multiple tags in one time thus increase the efficiency of data processing. In comparison with barcode or magnetic system, no direct contact between a RFID reader and the tagged item is needed as it uses radio wave which can be classified as low, high, ultrahigh frequencies ranging from $125 \mathrm{KHz}-5.875 \mathrm{GHz}$. The reading distance can be as great as 15-25 meters if powered in active RFID (Goodrum et al., 2006). In addition to reading data, it is possible to write data back to the RFID tag, which greatly increases the interaction between items, system, and people. All these advantages enable a better real-time information visibility and traceability.

$<<$ Insert Table 1 Here $>>$

\subsection{RFID technology in various industries}

Owing to its advantages, the RFID technology has been used in a wide range of areas. 
Walmart is a big figure in promoting RFID technology; using its dominant position in industries, Walmart requires its top suppliers at the upstream to adopt RFID technology which will facilitate operations towards the downstream (e.g. distribution, wholesale, and retail) (RFID Journal, 2003; Huang et al., 2008). RFID is also widely used in facilitating electronic transaction (e.g. Toll collection in U.S., Octopus card in Hong Kong, or Oyster card in London), logistic and supply chain management (e.g. the internet of things), manufacturing and assembly (e.g. the assembly of cars), express service (e.g. American express), scientific research (e.g. tracing snakes and migratory birds), medicine (e.g. identifying a specific patient), security (e.g. access control). It is envisaged that the technology, with its superior capability to provide real-time information, will significantly improve the effectiveness and efficiency of the above processes. More up-to-date applications of RFID can be found in the RFID Journal which devotes solely to the technology and its many business applications. Many governments and institutions take RFID as a strategic direction.

The research on RFID is developing popularity. In the manufacturing industry, for example, RFID was recognised as an automatic objective identification (auto-ID) technology. Notably, research is conducted to investigate how RFID technology can deal with real-time field information, and consequently how it can reengineer traditional manufacturing systems such as the development of wireless manufacturing, assembly shop-floor configuration, and adaptive assembly planning and control (e.g. Huang et al., 2007; 2008a; 2008b). According to Tajima (2007), the largest area of applications of RFID was logistic and supply chain management (LSCM). Li and Visich (2006) attempted to summarise RFID benefits in LSCM by listing 39 benefits across the supply chain. Tajima (2007) reported that research of RFID in LSCM, either adopting an empirical or an analytical approach, was mainly motivated by the same research question: what is the realistic value of RFID? In comparison with the studies focused on a given industry, a future vision is to integrate the above process of manufacturing, distributions, and sale, and to achieve an ambition of the 'Internet of Things'. According to Teresko (2003), the 'Internet of Things' refers to a global network of computers and objects in which computers are able to identify and store information on any object, anywhere in the world, instantly.

\subsection{RFID in construction}

The construction industry has characteristics that separately are shared by other industries but in combination appear in construction alone (Hillebrandt, 1984). The areas seeing the applications of RFID in other industries can also be seen in construction while with heterogeneity. To the construction industry, RFID technology is not completely new. Early in 1995, Jaselskis et al. (1995) envisaged its potential applications in construction, including concrete processing and handling, cost coding for labour and equipment, and materials control. Since that, a few more studies have been conducted to explore potential applications of RFID in this industry. 
Jang and Skibniewski (2009) developed an embedded system for tracking construction assets (e.g. materials and equipment) by combining radio and ultrasound signals. Likewise, Goodrum (2006) implemented the technology for tool tracking on construction job sites. Dziadak et al. (2009) developed a model for the 3D location of buried assets based on RFID technology. Domdouzis et al. (2007) explored the applications of RFID in the construction industry including automated tracking of pipe spools and other valued items, and an on-site inspection support system. Tzeng et al. (2008) explored the influence of combination manners of RFID and interior decorating materials on RFID system recognition. Yin et al. (2009) developed a precast production management system using RFID technology in the face that prefabrication is increasingly adopted in construction. Wang (2008) explores how the RFID technology can be used to enhance construction quality inspection and management. Chin et al. (2008) developed an information system to support the logistics and progress management based on this strategy by combining the RFID and 4D CAD.

However, not many applications of RFID have been seen in real-life construction practices in spite of the desire for this technology. In Hong Kong, for example, institutions are starting to explore the use of RFID in construction. The Mass Transit Railway Corporation (MTRC) has introduced RFID in their projects. The Housing Authority (HA) encourages the applications of RFID in their projects but starting from a pilot project. In universities, students are encouraged to explore how the incapability of CPM can be improved by using RFID. It was introduced as a cutting-edge technology yet to be highly promoted in the construction industry. The possible reasons are many. Project managers may not have been fully aware of the potential uses of RFID in construction. Various technical, financial, or ethical hurdles may also prevent it from being widely adopted in this heterogeneous industry. These encourage the authors to investigate a comprehensive list of potential applications of RFID in CPM by envisaging its advantages and hurdles.

\section{Methods}

A research framework borrowing ideas from the manufacturing industry was proposed to guide the investigation in this study. In manufacturing, a Wireless Manufacturing Framework was developed to achieve a better working environment with real-time information visibility and traceability for improving the effectiveness of managerial decisions and operational efficiency (Huang et al., 2008). These frameworks normally comprises of five layers from bottom to top: traceable objects with RFID or other auto-ID technologies, smart objects, smart gateway, shop floor gateway, and enterprise application systems. Similar to borrowing the lean production idea from Toyota, frameworks in manufacturing may be applicable to construction. But the research reported herein focuses on RFID and how it as a fundamental part of the frameworks can be used in construction

Bearing the research framework in the mind, 16 researchers were divided into 3 
groups to collect data for this research. This was organised as a studio project to be completed within four weeks. The students have learnt CPM in other subject while this studio project focuses on incapability of CPM and sees how RFID technology can help with particular emphasis placed on real-life PM practices. They were encouraged to start the explorations from a review of the literature which reports the RFID technology in terms of its technical specifications and its applications in various industries including construction. They were further involved in the exploration of the scenarios in CPM through interviewing project managers, experts, and conducting case studies.

Four principles behind the investigation differentiate itself from the previous studies alike.

(a) Comprehensiveness of the investigation. Unlike previous studies introducing uses of RFID in a piecemeal fashion, this research aims to investigate a comprehensive list of RFID applications that can inform more in-depth studies. In addition to a comprehensive literature review, brainstorming is therefore adopted as an effective tool for generating as many ideas as possible. Moreover, a matrix as shown in Table 2 is given as guideline for exploring the potential applications.

(b) Hypothetical cases. For investigating the potential uses of RFID, a large number of hypothetical scenarios were formulated as meaningful representatives of typical CPM practices from more than one project. Huang et al. (2007; 2008a) adopted a similar approach by formulating a hypothetical job shop and a product line, and this proved to be very effective for the ease of understanding and discussion.

(c) Innovative uses of RFID in construction. In addition to the existing applications, those more innovative ones that have not been seen in the construction industry are highly desired in this research. The investigators have been encouraged to make some reasonable assumptions that technical or financial hurdles of current RFID technology will be eliminated in the near future. The RFID technology can also be combined with other technologies such as sensors and digital technology to fulfil an innovative use.

(d) Cross-sector learning. Applications of RFID in other industries can be replanted to CPM by examining its applicability. The formulation of the research team has included researchers from manufacturing, construction, RFID, and IT background.

$<<$ Insert Table 2 Here $>>$

\section{Case scenarios for applying RFID technology in construction project management}

This section describes the case scenarios for applying RFID in CPM. A large number of scenarios have been formulated but for easier discussion, they were distilled into representative ones including management of materials, men (labour and other personnel), and machinery $\left(\mathrm{M}^{3}\right)$. It is known that that up to $70 \%$ of the overall 
construction cost is direct cost relating to materials, men, and machinery (Patrascu, 1988). CPM, in a sense, is to manage materials, men, and machinery.

\subsection{Management of materials}

\subsubsection{Logistic and Supply chain management (LSCM)}

In a typical material supply chain, construction materials ordered were shipped or transported by trucks from factory to material distributors, and then on-site warehouse. Material information such as manufacturer, quantity, specifications, etc. should be readily available to decision makers such as buyers in the head office, project managers on site, and truck drivers on the road. Real-time information is more important when Just-In-Time (JIT) method is adopted to deal with compacted jobsites commonly seen in congested urban areas. For example, a concrete caisson foundation using a JIT site cast technology needs real-time information and coordination amongst offsite concrete mixers, tilting drum truck drivers, and site workers, otherwise the concrete could be delayed or reach earlier, thus cause loss. Steel members or prefabricated components (e.g. outriggers, composite beams) should be transported to sites timely or the construction process will be disrupted or there is no enough space to store these items. Ideally, material information such as size, weights, handling instructions, and assembly methods, should also be available to construction workers. In these case scenarios, real-time information visibility and traceability is highly desired and RFID technology can be implemented for this purpose.

Material information will be stored in RFID tags pasted on the materials. Similar to Wal-Mart's practice to tag its food and drink, this has been seen in construction to tag big construction components. What is more encouraging is that today's material manufacturers are open to RFID technology in tagging their products. Locations of materials can be efficiently tracked by combining it with Global Positioning System (GPS) and Geographic Information System (GIS) (Lu et al., 2007). Meanwhile, concerns are many. The information that is tailor-made for construction uses (e.g. assembly of prefabricated components) is yet to be explored. The reading range and the accuracy of information become critical since construction components are normally large in dimensions. The unit price for RFID should be lowered before it can be massively adopted in construction LSCM.

\subsubsection{Inventory management}

Material inventory management is of particular importance in construction. A proper amount of materials in stock can maintain a healthy cash flow for a contractor. This is particularly true when today's companies tend to purchase materials from global market, meanwhile storing them in warehouse and construction sites do not come from free. In addition, a good inventory management of materials can ensure the smoothness of construction processes. Real-time inventory information can further facilitate another round of material management processes such as ordering, transporting, stocking, and using. Traditionally these were done manually through 
sending paper documents back and forth. With their obvious weaknesses, traditional inventory management methods turned out to be of low efficiency and effectiveness. RFID technology can be implemented to improve the inventory management of construction materials.

At the storage area, long-range RFID readers will be installed to retrieve the material information embedded in RFID tags that were attached on materials. When the newly arrived materials are placed in the area, the readers read the tags and update the inventory database automatically. When the materials are taken out for using, the system works in a reverse way where the inventory is deducted from the database. The RFID technology can improve productivity by reading all the information in a go, and updating it automatically. It is also easier for construction workers to find the right materials by tracing the information attached on materials.

An important point coming up from the research is to integrate the LSCM and the inventory management with RFID embedded information flowing seamlessly through the two processes. The integration should be further aligned with the heterogeneous construction processes which were characterised with JIT, lean production, efficiency nowadays. This resonates with the vision of the "Internet of Things" where ubiquitous IT and auto-ID can enable identify and store information on any object and in anywhere.

\subsubsection{Quality assurance}

RFID technology can be used to improve construction quality through a number of ways. For example, it was used by the MTRC to indicate the depth of piles as there were construction practices that piles did not actually penetrate to the designated depth. In this case, RFID tags can be planted into the pile ends and their radio signals will indicate the depth that the piles have actually penetrated into the ground. RFID can also help anti-counterfeit materials. With RFID tags being applied, each material will have a unique serial number from the manufacturer. Similar to the practice in library to attach RFID tags in books, these tags can be placed in materials. Project managers can double-check the materials to ensure the materials used are provided by a qualified supplier and are used appropriately. Once the materials were used, the embedded information can be used in the future such as showing buried assets, or facilities management. By implanting RFID into concrete blocks, it can facilitate the quality test, for example, to indicate the concrete testing samples. The advantage of using RFID tags over the use of paper labels is that the former are set into the concrete and become irremovable unless destroying it. Therefore, it prevents the concrete blocks from unintentionally being replaced.

The list of innovative applications of RFID in ensuring construction quality can be longer. It is not that RFID is a mysterious ingredient but it can improve information visibility and traceability thanks to its advantages. For example, no direct contact is needed to read its signal. In comparison with bar-code, the information in RFID can 
be better retrieved, particularly on site with a dusty or muddy environment. RFID tags are thin and flexible, which can be set into construction materials.

\subsubsection{Waste management}

Construction and demolition (C\&D) waste is defined as the waste that arises from construction, renovation and demolition activities (Shen et al., 2004; Poon et al., 2004). During the past decades, construction and demolition (C\&D) waste issues have received increasing attention around the world. Normally, C\&D waste should be delivered to landfill or designated places. Research shows that illegal dumping of waste is a serious problem yet to be solved. In Hong Kong, for example, a "trip ticket system” is implemented to prevent illegal dumping. The trip ticket system is a recording system for trucks transporting waste, ensuring that each type of waste is directed to the appropriate facility for reuse, recycling, recovery or disposal. Nonetheless, the effectiveness is reported to be insufficient, and in this case the RFID technology can help.

A RFID reader/writer is installed at the exit of the construction site. Information such as departure time, waste type, target places will be written into the RFID tag as a beacon placed on the truck. Upon the arrival of the truck at the designated destination, another RFID reader/writer will read the information, match it, and give or deny the access. Information in the RFID tags can be read and written automatically without intervention of the contractor or lorry drivers thus illegal dumping can be reduced. The RFID system can be combined with other systems, e.g. waste charging scheme, to enable a more efficient management of C\&D waste.

\subsection{Management of men}

\subsubsection{Access control and labour attendance record}

Construction sites have specific needs for access control; an effective access control system can keep the site, staff, and assets secure; if combined with an attendance checking system, it can provide time and attendance record as a basis for further uses such as allocating works, calculating wage, and so on. Current access control and labour attendance check, undertaken manually by punching in and out their timecards, have many drawbacks. For example, it is time-consuming. In the construction sites we investigated, there was often a long queue for checking-in after the workers lunched out. Although rare, there are cases that workers cheat the attendance check system. Sometimes, there are disputes over wages which are often calculated on an hourly rate and workers' attendance record. RFID can be implemented to develop a more efficient and accurate access control and labour attendance record system.

Each worker will have a RFID card which could be integrated with existing card (e.g. railway card) to record their IDs, photos, access authorities, and companies when there is more than one sub-contractor. A reader at the entrance/exit of the construction site will retrieve the information, match it, and give or deny access. The system will 
record the entering and exiting times automatically and this information will be used for calculating wages by a computer system. In view of the potential cheating, this RFID system can be combined with biometric information such as fingerprints, iris scanning, or facial recognising. This proposed system is hardly new in other areas such as border controls but in construction it is yet to be widely introduced.

\subsubsection{Safety of men}

Construction safety is a key issue in modern CPM. RFID can be implemented to improve safety performance on site. Research has shown that a major problem accounting for site accidents is that workers do not wear their safety gears properly, particularly in a hot or humid working environment such as a construction site. It is suggested to put RFID tags in safety gears including safety helmet, fluorescent jacket, safety boots, and belt. A system is to detect whether they have worn the gears properly, for example, by detecting their relative positions in line with strengths of signals. Nonetheless, the algorithm for this is yet to be developed.

Real-time location information on the whereabouts of people within a site can be very helpful in construction safety management. For example, Spanish construction companies FCC and ACCIONA implement employee tracking solution for tunnel workers' safety using its existing Wi-Fi network as the infrastructure (Ekahau Inc., 2009). By using RFID technology, an affordable employee tracking system can be developed to provide real-time information, which is critical for construction safety. Meanwhile, the system of this kind needs to solve problem which belong to a domain called localization using RFID technology. Authors have discussed this in the construction sector (e.g. Jang and Skibniewski, 2009; Pradhan, 2009; Khoury and Kamat, 2009). In addition, the ethical issue for tracking construction workers on site also needs to be taken into consideration in this case.

Another imaginative application is to develop an RFID-enabled safety precaution system that could inform workers of potential risks on site using ubiquitous RFID. In this case, a construction site will be divided into different zones, with each having a different colour (e.g. red, green, and amber) to indicate the potential dangers. All the potential risks such as fire, electrical, chemical hazards were registered in RFID tags that are ubiquitous on site. By linking the tags with a RFID reader and an alarming system, it is possible to give workers instructions and precautions of the potential risks. RFID has the advantages to provide this real-time visible and traceable information on site. Nonetheless, a lot of concerned problems need to be solved before the system can be really implemented. Besides the concerns for capturing real-time information of workers on-site, how to zone construction site, and how to register potential risks using RFID tags are all unresolved issues. The technical and financial challenges with this RFID-enabled safety precaution system also need to be further explored.

\subsection{Management of Machinery}




\subsubsection{Tracking of machines and tools}

Construction machinery ranges from large-scale machines such as cranes and excavators to smaller tools such as pneumatic breakers, welding machines, and wrenches. Managing machines and tools efficiently is not only to manage them as assets but also to ensure the smoothness of scheduled construction works. The real-time visibility and traceability of machinery become more important when the construction site is big (e.g. civil work) and the placement of machines and tools becomes more critical. Domdouzis et al. (2007) described several similar scenarios. Tracking of machinery is equally important as tracking of men but the former is even more difficult; project managers can talk using walkie-talkie or mobile phone in tracking men but this is not applicable to the tracking of machinery. RFID technology can help in this case.

RFID tags can store the log of borrowing and returning thus help tracking the machines and tools, preventing lost, misplacement, or burglar. This can be further enhanced by linking the log with the labour attendance recording system as introduced in section 4.2.1. In addition, RFID technology can be applied to locating machines and tools. Similar to the tracking of men, this belongs to the problem domain of localization. RFID technology can help solve the problems for tracking of machines and tools with its strengths of wave length, and contactless.

\subsubsection{Machine operation and record}

A machine operation permission system can be developed using RFID technology. In order to start the engine and operation of heavy machines like cranes and excavators, operators have to flash their RFID card in front of a RFID reader installed in the machine operation room. They need to do it again when leaving or stopping the machines. Ideally, this permission should be related to the qualifications and experiences of authorised persons which can be indicated in a RFID card. Information such as the operator and operation time are recorded and stored in a central system. This allows a project manager to monitor the utilization history of every machine and to estimate its depreciation. This information will also be very useful for inspection, maintenance, or calculation of quantities.

In this system, RFID presents a few advantages over other similar technologies. For example, it can read and write back information; it can store a relative large amount of information. It is recommended that the system should be developed by working with the machine manufacturers who know its specifications better.

\subsubsection{Machine maintenance record}

Heavy machines are often a company's valuable assets. They are also critical to ensure the smoothness of construction processes. To ensure their quality and functionality, regular checking and maintenance of machines is of absolute necessity. Currently this is conducted manually and the records are kept in paper forms. This can 
be improved by using RFID technology. While checking and maintaining the machines, the inspectors or maintenance technicians can use a handheld RFID device (e.g. a PDA) to scan the RFID tags on the machine. All maintenance records such as time of inspection, the personnel who conducts the checking, conditions of the machines, and repair work done, can be read. After finished the inspection and maintenance, the information can be saved into the tags immediately and updated in the central system for further use.

\section{Hurdles and research perspectives towards RFID integration}

RFID is a proven technology that is being widely used in many areas. Owing to its various advantages, RFID can also be used in a wide range of CPM scenarios that require real-time information with visibility and traceability. Nonetheless, hurdles ahead are to be overcome. These include (1) technical hurdles; (2) costs; and (3) health and ethical issues.

There are many technical problems need to be solved before the above envisaged scenarios can become realities. Some of these problems are commonly seen in other industries, while others are unique to the construction industry. One emerging issue is that the low degree of standardization. There is no global public body that governs the frequencies used for RFID. The frequencies used for RFID in one country are currently incompatible with those in other countries. Furthermore, there is no standard information structure that facilitates share among supply chain partners although RFID-generated product information can provide unprecedented visibility in the supply chain. Reading range/distance should be increased, particularly in respect of construction components which are often large in size. Normally the reading distance range is less than $16 \mathrm{~cm}$ but using active RFID and being powered the reading distance can be as large as 15-25m (Goodrum, 2006). However this will add to the cost when using active RFID. While having its advantages, radio signal can be seriously interfered by steel objects, water, or other radio frequency signals (Jaselskis and El-Misalami, 2003). This is particularly true for construction sites where steel members are widely seen.

In comparison with barcode systems, RFID technology is still relatively expensive although the cost has been reduced over the past years. As mentioned above, when reading distance is concerned, expensive active RFID tags are often used, which makes the technology less competitive. Clearly isolating benefits contributed by RFID technology and demonstrating them to contractors are critical for this technology to be widely adopted in CPM. In addition, the health issues related to RFID are still in doubt although there is no report to prove whether radio frequency is harmful to human. Ethical issues should also be taken into consideration, in particular for the case scenarios above where their positions were tracked or their information was captured.

Nonetheless, a contractor should be forward-looking in exploring the RFID 
technology in CPM. Researchers have given many insightful recommendations on how to achieve its wider applications in practice (e.g. Jaselskis and El-Misalami, 2003; Domdouzis et al., 2007). By appreciating these recommendations and the ever-changing information age, this study proposes some research perspectives characterised as "integration":

(1) Integrate with the developments of RFID in other industries. There is a debate that construction is not a heterogeneous industry; the features in the construction industry (e.g. bespoke design, fixed-position layouts, complex supply chain, JIT) can all be seen in others. Therefore, the advancements of RFID in other industries can also be applied in construction. Investigation of RFID in construction should integrate itself with the developments outside the sector such as technical advancements, information standard, radio frequency regulations, etc.

(2) Integrate with Building Information Model (BIM). BIM is envisaged to bring a paradigm shift in CPM through managing building information in a systematic way and fostering a collaborative working environment ( $\mathrm{Li}$ et al., 2009). The discussions of BIM are pervasive in the sector but a big problem is that they failed to explore how a BIM can really talk to a construction project in a real-time manner. RFID, with its real-time information with visibility and traceability, can bridge the interface between a BIM and a real project.

(3) Integrate with people, project, and process. RFID is not silver bullet but gains its momentum through providing real-time information throughout people, project, and process in construction. Future research should be undertaken to investigate how RFID can integrate into these rather than disrupting them. This is not a pure technical issue but about how to manage technology to be a facilitator.

\section{Conclusions}

This paper envisages the promise for RFID technology to be implemented in construction project management (CPM). It is found that RFID shows great potential in improving CPM goals such as time, quality, cost, safety, and environment by applying it in the management of materials, labours, and machinery. The great potential comes from the increasing importance of information in contemporary CPM. Managing a construction project is essentially making a web of decisions across its process based on the information available. RFID technology can largely enhance the real-time information visibility and traceability in CPM thanks to its unique advantages.

In spite of its great potential, RFID is slowly adopted in the construction industry. There are two possible ways to achieve its wider applications. One is to inform the industry of the potential in an effective way. The scenarios identified in this work, animated later using Google Sketch Up, can serve as a vehicle for better communicating the potential of RFID to construction practitioners. Another way is to realize the systems as suggested in this study through overcoming its many technical, financial, ethical hurdles. Future studies are recommended integrating itself (1) with the developments of RFID in other industries, (2) with Building Information Model 
(BIM), and (3) with people, project, and process in construction.

\section{References}

Angeles, R. (2005). RFID Technologies: Supply-Chain Applications and Implementation Issues. Information Systems Management, 22(1), 51-65.

Bennett, J. (1985) Construction Project Management, Butterworth, London.

Chappell, G., Durdan, D. G., Gibert, G. L., Ginsburg, J. S., \& Tobolski, J. (2002).

Auto-ID on delivery: The value of Auto-ID technology in the retail supply chain.

Auto-ID Center, www.autoidcenter.org.

Chin, S., Yoon, S. ; Choi, C. and Cho, C. (2008), RFID+4D CAD for Progress Management of Structural Steel Works in High-Rise Buildings, Journal of Computing in Civil Engineering, 22 (2), 74-89.

Domdouzis K., Kumar B. \& Anumba C. J.: 'Radio Frequency Identification (RFID) Applications: A Brief Introduction', Advanced Engineering Informatics - special issue on RFID, Vol. 21, 2007, pp 350-355.

Dziadak, K., Kumar, B., and Sommerville, J. (2009), Model for the 3D Location of Buried Assets Based on RFID Technology, Journal of Computing in Civil Engineering, 23(3), 148-159.

Flanagan, R. and Lu, W. (2008) Making informed decisions in product-service systems, In: Proc. IMechE Conference, Knowledge and Information Management Through-Life, Institute of Mechanical Engineers, 24 June 2008, London.

Goodrum, P. M., McLaren, M. A., and Durfee, A. (2006), The application of active radio frequency identification technology for tool tracking on construction job sites, Automation in Construction, 15(3), 292-302.

Hillebrandt, P.M. (1984), Analysis of the British Construction Industry, London: Macmillan Press.

Huang, G.Q, Zhang, Y.F., Chen, X. and Newman, S.T. (2008b), RFID-enabled real-time wireless manufacturing for adaptive assembly planning and control, Journal of Intellectual Manufacture, 19, 701-713.

Huang, G.Q., Zhang, Y.F., Jiang, P.Y. (2007), RFID-based wireless manufacturing for walking-worker assembly islands with fixed-position layouts, Robotics and Computer-Integrated Manufacturing, 23, 469 - 477.

Huang, G.Q., Zhang, Y.F., Jiang, P.Y. (2008a), RFID-based wireless manufacturing for real-time management of job shop WIP inventories, International Journal of Advancement of Manufacture Technology, 36, 752-764.

Jang W.K. and Skibniewski, M.J. (2009), Embedded system for construction asset tracking combining radio and ultrasound signals, Journal of Computing in Civil Engineering, 23 (4), 221-229.

Jaselskis E.J., Anderson, M.R., Jahren, C.T. Rodriguez, Y., and Njos, S. (1995), Radio-frequency indentification applications in construction industry, ASCE Journal of Construction Engineering and Management, 121 (2), 189-196.

Jaselskis, E.J. and El-Misalami, T. (2003), Implementing Radio Frequency Identification in the Construction Process, Journal of Construction Engineering 
and Management, 129 (6), 680-688.

Kärkkäinen, M., \& Holmström, J. (2002). Wireless product identification: Enabler for handling efficiency, customization and information sharing. Supply China Management, 7(4), 242-252.

Khoury, H.M., and Kamat, V. R. (2009), Evaluation of position tracking technologies for user localization in indoor construction environments, Automation in Construction 18), pp $444-457$.

Li, H., Lu, W.S., and Huang, T. (2009), Rethinking project management and exploring virtual design and construction as a potential solution, Construction Management and Economics, 27:4,363 - 371.

Liying Shen, Weisheng Lu, Michael, C.H. Yam (2006), Contractor Key Competitiveness Indicators (KCIs): A China Study, Journal of Construction Engineering and Management ASCE, 132(4), pp416-424.

Lu, M., Chen, W., Shen X.S., Lam, H.C., and Liu, J.Y. (2007), Positioning and tracking construction vehicles in highly dense urban areas and building construction sites, Automation in Construction, 16(5), 647-656.

Patrascu, A. (1988) Construction Cost Engineering Handbook, Taylor \& Francis, London.

Poon, C.S., Yu, A.T.W., Wong, S.W. and Cheung, E. (2004), Management of construction waste in public housing projects in Hong Kong. Construction Management and Economics, 22(7), 675-689.

Pradhan, A., Ergen, E., Akinci, B. (2009), Technological Assessment of Radio Frequency Identification Technology for Indoor Localization, Journal of Computing in Civil Engineering, 23(4), pp230-238.

Schultz,M., \&Woods,M. (2002). Focus on the supply chain: Applying Auto-ID within the Distribution Center, www.fmi.org/technology/ FMI_PWC_Dist.pdf.

Shen, L.Y., Tam, V.W.Y., Tam, C.M. and Drew, D. (2004). Mapping approach for examining waste management on construction sites. Journal of Construction Engineering and Management, 130(4), 472-481.

Tajima, M. (2007), Strategic value of RFID in supply chain management, Journal of Purchasing \& Supply Management 13 (2007) 261 - 273.

Teresko, J., 2003. Winning the wireless. Industry Week, June 1. URL: /www.indsutryweek.com/Archive.aspxS.

Tzeng, C.T., Chiang, T.C., Chiang, C.M. and Lai, C.M. (2008), Combination of radio frequency identification (RFID) and field verification tests of interior decorating materials, Automation in Construction, 18, 16-23.

Wang, L.C. (2008), Enhancing construction quality inspection and management using RFID technology, Automation in Construction, 17, 467-479.

Yin, S.Y.L., Tserng, H.P., Wang, J.C., and Tsai, S.C. (2009), Developing a precast production management system using RFID technology, Automation in Construction, 18, 677-691. 
Table 1 A comparison of RFID with its sister technologies

\begin{tabular}{|l|l|l|l|}
\hline & RFID technology & Barcode system & Magnetic strip \\
\hline Read rate & Fastest & Slow & Medium \\
\hline Storage capacity & Largest & Smallest & Modest \\
\hline Ease of reproducing a "fake" one & Difficult & Easy & Difficult \\
\hline Ease of positioning for sensing & Easy & Difficult & Easy \\
\hline Cost of a tag & Cheap & Cheapest & Expensive \\
\hline Ease of obtaining information & $\begin{array}{l}\text { Difficult (if } \\
\text { encryption is done) }\end{array}$ & Easy & Easy (use a reader) \\
\hline Knowledge of items' exact position & Easy & Difficult & Difficult \\
\hline Write & Possible & Impossible & Impossible \\
\hline
\end{tabular}

Table 2 A guideline for exploring RFID in project management

\begin{tabular}{|l|l|l|l|}
\hline & Materials & Man & Machinery \\
\hline Time & & & \\
\hline Cost & & & \\
\hline Quality & & & \\
\hline Safety & & & \\
\hline Environment & & & \\
\hline
\end{tabular}

